\title{
The biochemical recurrence-free rate in patients who underwent prostate low-dose-rate brachytherapy, using two different definitions
}

Nobumichi Tanaka1*, Isao Asakawa², Emiko Katayama², Akihide Hirayama ${ }^{1,4}$, Masatoshi Hasegawa ${ }^{2}$, Noboru Konishi ${ }^{3}$ and Kiyohide Fujimoto ${ }^{1}$

\begin{abstract}
Background: To assess the biochemical recurrence (BCR)-free rate in patients who underwent prostate low-dose-rate brachytherapy (LDR-brachytherapy), using two different definitions (Phoenix definition and PSA $\geq 0.2 \mathrm{ng} / \mathrm{mL}$ ).

Methods: Two hundreds and three patients who were clinically diagnosed with localized prostate cancer (cT1C-2CNOM0) and underwent LDR-brachytherapy between July 2004 and September 2008 were enrolled. The median follow-up period was 72 months. We evaluated the BCR-free rate using the Phoenix definition and the PSA cut-off value of $0.2 \mathrm{ng} / \mathrm{mL}$, as in the definition for radical prostatectomy. To evaluate an independent variable that can predict BCR, Cox's proportional hazard regression analysis was carried out.

Results: The BCR-free rate in patients using the Phoenix definition was acceptable (5-year: 92.8\%). The 5-year BCR-free rate using the strict definition (PSA $\geq 0.2 \mathrm{ng} / \mathrm{mL}$ ) was $74.1 \%$. Cox's proportional hazard regression analysis showed that a higher biological effective dose (BED) of $\geq 180 \mathrm{~Gy} 2$ was the only independent variable that could predict BCR (HR: 0.570, 95\% C.I.: 0.327-0.994, $p=0.048)$. Patients with a higher BED ( $\geq 180 \mathrm{~Gy} 2)$ had a significantly higher BCR-free rate than those with a lower BED (<180 Gy2) (5-year BCR-free rate: $80.5 \%$ vs. 67.4\%).
\end{abstract}

Conclusions: A higher BED $\geq 180$ Gy2 promises a favorable BCR-free rate, even if the strict definition is adopted.

Keywords: Prostate cancer, LDR-brachytherapy, Biochemical recurrence-free rate, BED

\section{Background}

Nowadays, low-dose-rate brachytherapy (LDR-brachytherapy) is one of the curative treatment options for non-metastatic prostate cancer [1-6] alongside radical prostatectomy and intensity modulated radiation therapy (IMRT). Usually, the cut-off value in the definition of biochemical recurrence is prostate specific antigen (PSA) of $0.2 \mathrm{ng} / \mathrm{mL}$ for patients who underwent radical prostatectomy [7], and the Phoenix definition (nadir $+2 \mathrm{ng} / \mathrm{mL}$ ) is used for patients who underwent definitive radiation therapy [8]. In several guidelines [9-11], the oncologic outcome of radiation therapy is considered in the same way as that of radical prostatectomy. However, it is inappropriate to compare the oncologic outcome between

\footnotetext{
* Correspondence: sendo@naramed-u.ac.jp

${ }^{1}$ Department of Urology, Nara Medical University, 840 Shijo-cho, Kashihara, Nara 634-8522, Japan

Full list of author information is available at the end of the article
}

surgery and radiation therapy using different definitions $(0.2 \mathrm{ng} / \mathrm{mL}$ vs. nadir $+2 \mathrm{ng} / \mathrm{mL})$. From a radiation oncologist's viewpoint, a cut-off value of $0.2 \mathrm{ng} / \mathrm{mL}$ is very strict, because the prostate gland itself is still present after radiation therapy. As long as different definitions are used, direct comparison of oncologic outcome between surgery and radiation therapy remains impossible. To address this issue, we evaluated the oncologic outcome in patients who underwent LDR-brachytherapy using both definitions of biochemical recurrence $(0.2 \mathrm{ng} / \mathrm{mL}$ vs. $2 \mathrm{ng} / \mathrm{mL})$.

\section{Methods}

Two hundreds and three patients who were clinically diagnosed with localized prostate cancer (cT1c-2cNOM0) and underwent LDR-brachytherapy between July 2004 and September 2008 were enrolled in this study. The 
patients' characteristics are shown in Table 1. The median age, PSA value at diagnosis, and follow-up period were 70.0 years (range: $51-80$ ), $7.4 \mathrm{ng} / \mathrm{mL}$ (range: 3.1 32.1 ), and 72.0 months (range: $2-107$ ), respectively. We evaluated the biochemical recurrence-free rate using the Phoenix definition. We also used the PSA cut-off value of $0.2 \mathrm{ng} / \mathrm{mL}$ to evaluate the biochemical recurrence-free rate with the same definition as that used for radical prostatectomy. If the PSA value after seed implantation reached $0.2 \mathrm{ng} / \mathrm{mL}$ or more and showed a confirmatory PSA of $0.2 \mathrm{ng} / \mathrm{mL}$ or higher, the patient was defined to have biochemical recurrence the first time a PSA increase was noted. If the PSA value did not fall to less than $0.2 \mathrm{ng} /$ $\mathrm{mL}$, the patient was defined to have biochemical recurrence at the date of seed implantation. A pathologist (K.N.), who was expert in prostate cancer diagnosis, centrally reviewed the Gleason score of all biopsy specimens. This study was performed in compliance with the Helsinki Declaration. The institutional review board approved this study, and informed consent was obtained from all patients after explaining the aim and methods of this study.

Table 1 Patients' characteristics stratified by biochemical recurrence using PSA $0.2 \mathrm{ng} / \mathrm{mL}$ definition

\begin{tabular}{ccccc}
\hline & $\begin{array}{c}\text { BCR (-) } \\
(\mathbf{n}=\mathbf{1 5 0})\end{array}$ & $\begin{array}{c}\text { BCR (+) } \\
(\mathbf{n}=\mathbf{5 3})\end{array}$ & $\begin{array}{c}\text { Total } \\
(\mathbf{n}=\mathbf{2 0 3})\end{array}$ & $\boldsymbol{p}$ value \\
\hline Age (year) & & & & \\
Median (range) & $70.0(51-80)$ & $69.0(55-79)$ & $70.0(51-80)$ & $0.654^{\S}$ \\
PSA at diagnosis \\
(ng/mL)
\end{tabular}

${ }^{*}$ Chi-square test and ${ }^{\S}$ Mann-Whitney $U$ test.

\section{Treatment}

Of all 203 patients, 141 patients did not receive neoadjuvant or adjuvant androgen deprivation therapy (ADT), 5 received adjuvant $\mathrm{ADT}$, and 4 received both neoadjuvant and adjuvant ADT. The remaining 53 received only neoadjuvant ADT. One hundred and forty-six underwent only seed implantation and 57 patients received combination treatment including external beam radiation therapy (Table 1).

Risk classification was according to D'Amico's risk classification [12]. The numbers of low-, intermediate-, and high-risk patients were 93, 92, and 18 patients, respectively (Table 2). Low-risk patients (cT2a, Gleason score 6 , and PSA $\leq 10 \mathrm{ng} / \mathrm{mL}$ ) and patients (cT2a and PSA $\leq 10 \mathrm{ng} / \mathrm{mL}$ ) whose Gleason score of $3+4$ with the rate of positive biopsy core less than $50 \%$ were treated by seed implantation alone. From July 2004 to April 2007, there were 95 patients who were treated with seed implantation at a prescribed dose of $145 \mathrm{~Gy}$, and 51 patients were treated at a prescribed dose of $160 \mathrm{~Gy}$ after May 2007. The other patients received combination treatment including external beam radiation therapy (EBRT). The prescribed dose was $110 \mathrm{~Gy}$. The target portion of EBRT was determined one month after seed implantation, and the patients received 45 Gy (in 25 fractions of $1.8 \mathrm{~Gy}$ per fraction) using $10 \mathrm{MV}$ photon energy. The clinical target volume included both the whole prostate and one third of the proximal seminal vesicle.

Of all patients, 64 patients were treated with a preplanning method and 139 with an intraoperative planning method by modified peripheral loading techniques using Mick's applicator [13].

\section{Postdosimetric evaluation}

The therapeutic planning and post-implant dosimetric evaluation were performed using Interplant Version 3.3 (CMS, Inc., St. Louis, USA) planning system.

Post-implant CT scanning and post-implant dosimetric studies were performed by one radiation oncologist (A.I.) at 1 month after seed implantation. The dosimetric parameters analyzed in this study were the minimal percentage of the dose received by $90 \%$ of the prostate gland (\%D90), the percentage prostate volume receiving $100 \%$ of the prescribed minimal peripheral dose (V100), and the biological effective dose (BED). BED was calculated to evaluate an independent factor that can predict PSA bounce, and an $\alpha / \beta$ ratio of 2 was used [14].

\section{Statistic analysis}

The biochemical recurrence-free rate was estimated by the Kaplan-Meier method. A log-rank test was used for between-group comparison. The statistical difference between the recurrence group and the non-recurrence 
Table 2 Patients' characteristics stratified by biochemical recurrence using PSA $0.2 \mathrm{ng} / \mathrm{mL}$ definition

\begin{tabular}{|c|c|c|c|c|}
\hline & $\begin{array}{c}\text { BCR (-) } \\
(n=150)\end{array}$ & $\begin{array}{l}\text { BCR (+) } \\
(n=53) \\
\end{array}$ & $\begin{array}{c}\text { Total } \\
(\mathrm{n}=\mathbf{2 0 3})\end{array}$ & $p$ value \\
\hline \multicolumn{5}{|c|}{ D'Amico risk classification } \\
\hline Low & 65 & 28 & 93 & \\
\hline Intermediate & 70 & 22 & 92 & \\
\hline High & 15 & 3 & 18 & $0.400^{*}$ \\
\hline \multicolumn{5}{|l|}{ BED (Gy2) } \\
\hline Median (range) & $183.8(136.4-244.0)$ & $171.8(120.3-227.5)$ & $180.6(120.3-244.0)$ & $0.009^{\S}$ \\
\hline \multicolumn{5}{|l|}{ D90 (\%) } \\
\hline Median (range) & $110.6(90.0-136.9)$ & $108.6(79.8-126.2)$ & $110.3(79.8-136.9)$ & $0.106^{\S}$ \\
\hline \multicolumn{5}{|l|}{ V100 (\%) } \\
\hline Median (range) & $94.5(85.5-99.5)$ & $93.9(77.8-98.5)$ & $94.3(77.8-99.5)$ & $0.124^{\S}$ \\
\hline \multicolumn{5}{|l|}{ UD30 (\%) } \\
\hline Median (range) & $139.2(99.4-200.3)$ & $140.6(104.2-197.9)$ & $139.2(99.4-200.3)$ & $0.785^{\S}$ \\
\hline \multicolumn{5}{|l|}{$\mathrm{R} 100(\mathrm{~mL})$} \\
\hline Median (range) & $0.01(0.0-1.19)$ & $0.04(0.0-0.51)$ & $0.02(0.0-1.19)$ & $0.207^{\S}$ \\
\hline
\end{tabular}

${ }^{*}$ Chi-square test and ${ }^{\S}$ Mann-Whitney $U$ test, BED: biological effective dose.

group for categorical variables was tested by the chisquare test, while that for continuous variables was tested by the Mann-Whitney $U$ test. To evaluate an independent variable to predict biochemical recurrence, Cox's proportional hazard regression analysis was carried out.

All statistical analyses were performed using PASW Statistics 17.0 (SPSS Inc., Chicago, IL, USA). All $p$ values of less than 0.05 were considered statistically significant.

\section{Results}

Of all patients, 19 patients showed biochemical recurrence according to the Phoenix definition during the follow-up period. The 5-year biochemical recurrencefree rate was $92.8 \%$ (Figure 1). The 5-year biochemical

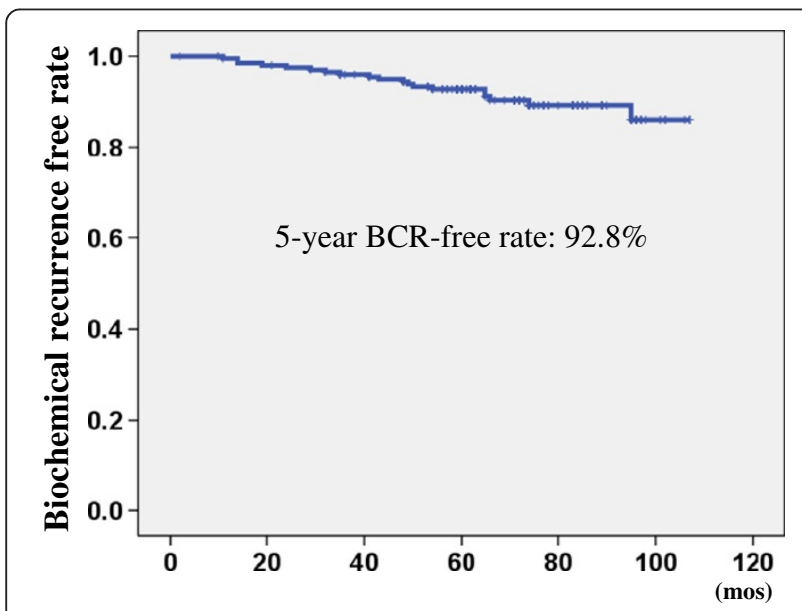

Figure 1 The biochemical recurrence-free rate using the Phoenix definition BCR: biochemical recurrence. recurrence-free rate in low, intermediate, and high-risk patients was $93.5 \%, 91.8 \%$, and $94.1 \%$, respectively. There was no significant difference between the different risk groups (Figure 2). Regarding clinicopathological parameters (e.g. PSA, Gleason score, age, clinical T stage, BED, D90 (\%), and V100), there were no significant differences between patients who showed biochemical recurrence and those who did not show recurrence.

On the other hand, 53 patients showed biochemical recurrence during the follow-up period according to the definition of PSA $\geq 0.2 \mathrm{ng} / \mathrm{mL}$. The 5 -year biochemical recurrence-free rate was $74.1 \%$ (Figure 3 ). The 5 -year biochemical recurrence-free rate in the low, intermediate, and high-risk patients was $71.0 \%, 75.4 \%$, and $83.3 \%$,

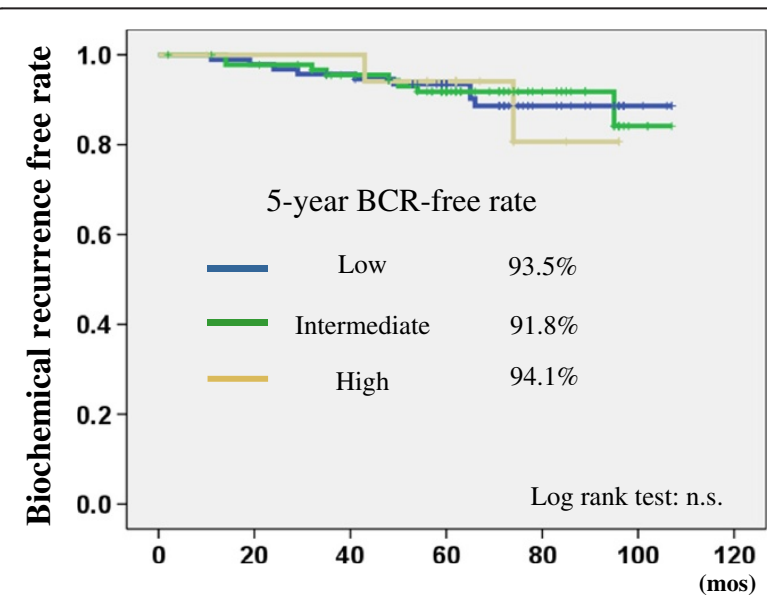

Figure 2 The biochemical recurrence free rate stratified by D'Amico risk classification using Phoenix definition BCR: biochemical recurrence. 


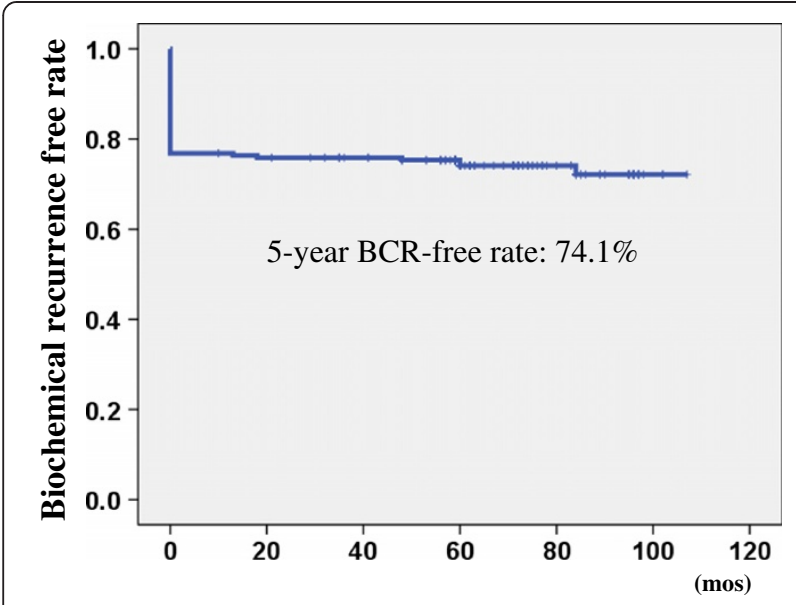

Figure 3 The biochemical recurrence-free rate using the definition of PSA $\geq 0.2 \mathrm{ng} / \mathrm{mL}$ BCR: biochemical recurrence.

respectively. There was no significant difference between the different risk groups (Figure 4). Among clinicopathological parameters, BED in the non-recurrence group was significantly higher than that in the recurrence group $(\mathrm{p}=$ 0.009 ). In all 53 patients who showed biochemical recurrence according to the definition of PSA $\geq 0.2 \mathrm{ng} / \mathrm{mL}, 19$ (35.8\%) met the Phoenix definition, 4 (7.5\%) had a PSA value $\geq 1.0 \mathrm{ng} / \mathrm{mL}, 11(20.8 \%)$ had a PSA value between 0.5 and $0.9 \mathrm{ng} / \mathrm{mL}$, and $19(35.8 \%)$ had a PSA value between 0.2 and $0.5 \mathrm{ng} / \mathrm{mL}$, respectively (Table 3 ).

Cox's proportional hazard regression analysis showed that a higher BED of $\geq 180$ Gy 2 (median BED of all patients) was the only independent variable that could predict biochemical recurrence after seed implantation (HR: 0.570, 95\% C.I.: 0.327-0.994, $\mathrm{p}=0.048$ ). Patients with a higher BED ( $\geq 180$ Gy2) had a significantly lower biochemical recurrence rate than those with a lower

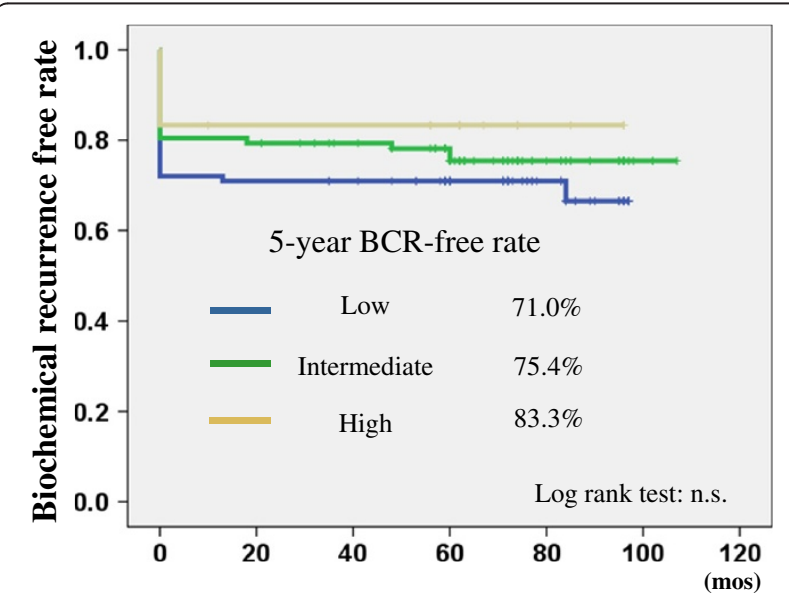

Figure 4 The biochemical recurrence free rate stratified by D'Amico risk classification using PSA $0.2 \mathrm{ng} / \mathrm{mL}$ definition BCR: biochemical recurrence.
Table 3 The number of patients and proportion stratified by PSA value of the last follow-up

\begin{tabular}{lll}
\hline PSA $(\mathbf{n g} / \mathbf{m L})$ & No of $\mathbf{p t s}$ & $\mathbf{( \% )}$ \\
\hline$<0.2$ & 150 & 73.9 \\
$0.2-0.49$ & 19 & 9.4 \\
$0.5-0.99$ & 11 & 5.4 \\
$1.0-$ & 4 & 2.0 \\
Nadir +2 & 19 & 9.4 \\
\hline
\end{tabular}

BED (<180 Gy2) (5-year biochemical recurrence-free rate: $80.5 \%$ vs. $68.4 \%, \mathrm{p}=0.025$ ) (Figure 5 ).

\section{Discussion}

LDR-brachytherapy has been one of the definitive treatment modalities for prostate cancer alongside radical prostatectomy and IMRT, not only for low-risk patients but also for intermediate and high-risk patients in recent years [11]. The most recent report revealed that the biochemical recurrence-free rate of patients who received LDR-brachytherapy was similar to that of patients who received radical prostatectomy [1-5]. The present study also showed a favorable oncologic outcome according to the Phoenix definition. However, using different definitions to compare the oncologic outcome of radiation therapy to that of radical prostatectomy is questionable. To address this issue, Critz et al. reported the oncologic outcome in patients who received LDR-brachytherapy in combination with EBRT using the same definition for biochemical recurrence as that for surgery [15]. They concluded that the biochemical recurrence-free rate was similar to that of radical prostatectomy using a large cohort study.

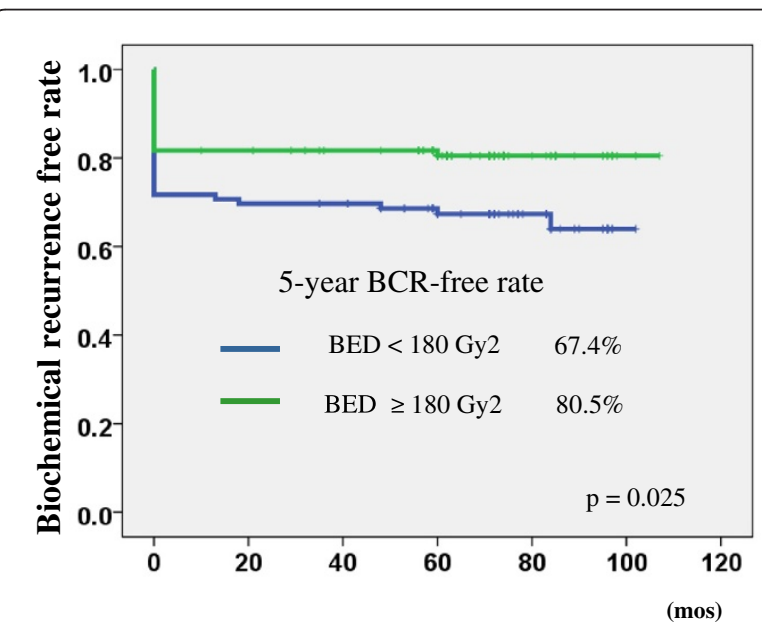

Figure 5 The biochemical recurrence-free rate stratified by biologically effective dose (BED) using the definition of $\mathrm{PSA} \geq 0.2 \mathrm{ng} / \mathrm{mL} \mathrm{BCR}$ : biochemical recurrence. 
The present study shows that the 5-year biochemical recurrence-free rate was $74.1 \%$ with a median follow-up period of 72 months. Most patients were classified as low- or intermediate-risk in this cohort. This result gives an unfavorable impression of seed implantation compared to radical prostatectomy. On careful consideration, however, the definition of PSA $\geq 0.2 \mathrm{ng} / \mathrm{mL}$ is very strict for radiation therapy, because the prostate gland itself remains after radiation therapy, while the prostate gland is essentially removed after radical prostatectomy. The remaining prostate gland secretes subtle PSA after radiation therapy. We also defined patients whose PSA did not decrease to less than $0.2 \mathrm{ng} / \mathrm{mL}$ as biochemical recurrence in this study. This definition is stricter than that of the Critz study [15]. They defined an increase in 3 consecutive PSA measurements as biochemical recurrence in patients with a follow-up period of less than 5 years. Indeed, 19 patients $(9.4 \%)$ in our study were defined as biochemical recurrence, but the PSA value at the last follow-up was between 0.2 and $0.49 \mathrm{ng} / \mathrm{mL}$. Taken together, $83.3 \%$ of patients showed a PSA value of less than $0.5 \mathrm{ng} / \mathrm{mL}$ at the last follow-up (Table 3).

Interestingly, Cox's proportional regression analysis showed that BED was the only independent variable that can predict biochemical recurrence in this study. We divided all patients by using a 180 Gy2 cut-off value of BED. This was the median value of BED for all patients. The Kaplan-Meier curve showed a significant difference in the 5-year biochemical recurrence-free rate (Figure 5: $80.5 \%$ vs. $67.4 \%, \mathrm{p}=0.025$ by the log rank test). This result indicated that a higher BED achieved a higher biochemical recurrence-free rate using PSA $\geq 0.2 \mathrm{ng} / \mathrm{mL}$ definition. Stone et al. also showed that BED was an independent variable that can predict the cancer-free rate of biopsy after seed implantation [16].

To compare the oncologic outcome in the same category such as IMRT vs. brachytherapy, it is appropriate to use the Phoenix definition. However, it is difficult to compare the oncologic outcome between different modalities (e.g. surgery vs. radiation therapy) using different definitions. Nielsen et al. reported that the biochemical recurrence-free rate was overestimated by the Phoenix definition compared to the standard definition (PSA $\geq 0.2 \mathrm{ng} / \mathrm{mL}$ ) in patients who underwent radical prostatectomy [17]. They insisted that the 5-year biochemical control rates with a definition of $0.2 \mathrm{ng} / \mathrm{mL}$ or higher should be compared with the 10-year biochemical control rates using the Phoenix definition.

In the present study, we demonstrated that most patients (83.3\%) achieved a PSA level of less than $0.5 \mathrm{ng} / \mathrm{mL}$ with a median follow-up period of 72 months after seed implantation. Patients who achieved a higher BED $\geq 180$ Gy2 also showed a favorable biochemical recurrence-free rate $(80.5 \%)$ using the definition of PSA $\geq 0.2 \mathrm{ng} / \mathrm{mL}$ (Figure 5).
We mostly treated the patients in the present study cohort by preplanned methods and the prescribed dose was 145 Gy for monotherapy (95/146: monotherapy pateints). We have now escalated the prescribed dose to 160 Gy and have adopted a real-time planning method. The BED of current patients is at least 180 Gy2. We believe that the oncologic outcomes of the current patient series will be more favorable than those in the present study. We should compare the oncologic outcomes of radical prostatectomy and LDR-brachytherapy using the same definition.

The limitation of this study is the small number of patients. We did not discuss an inter-risk group comparison due to the small number of patients, especially in the high-risk group $(n=18)$. Indeed, the oncologic outcomes of high-risk group were not different compared with other risk groups (low and intermediate) by either definition. Longer follow-up periods will allow further evaluation to make a definitive conclusion.

\section{Conclusion}

We reported the oncologic outcomes in Japanese patients who underwent LDR-brachytherapy with a median follow-up period of 72 months using different definitions of biochemical recurrence. Higher BED can promise a favorable biochemical recurrence-free rate, even if a strict definition is adopted.

\section{Abbreviations}

BCR: Biochemical recurrence; LDR-brachytherapy: Low-dose-rate brachytherapy; BED: Biological effective dose; PSA: Prostate specific antigen; ADT: Androgen deprivation therapy; EBRT: External beam radiation therapy; $\%$ D90: The minimal percentage of the dose received by $90 \%$ of the prostate gland; V100: The percentage prostate volume receiving 100\% of the prescribed minimal peripheral dose.

\section{Competing interests}

The authors declare that they have no conflicts of interest.

\section{Authors' contributions}

$\mathrm{TN}$, FK, and HM conceived of this study. Al, KM, and NT participated in data collection. FK and HA helped to draft the manuscript. TN carried out the statistical analysis. All authors read and approved the final manuscript.

\section{Author details}

'Department of Urology, Nara Medical University, 840 Shijo-cho, Kashihara, Nara 634-8522, Japan. ²Department of Radiation Oncology, Nara Medical University, Kashihara, Nara, Japan. ${ }^{3}$ Department of Pathology, Nara Medical University, Kashihara, Nara, Japan. ${ }^{4}$ Department of Urology, Nara Hospital Kinki University Faculty of Medicine, Ikoma, Nara, Japan.

Received: 20 March 2014 Accepted: 24 April 2014 Published: 6 May 2014

\section{References}

1. Grimm P, Billiet I, Bostwick D, Dicker AP, Frank S, Immerzeel J, Keyes M, Kupelian P, Lee WR, Machtens S, Mayadev J, Moran BJ, Merrick G, Millar J, Roach M, Stock R, Shinohara K, Scholz M, Weber E, Zietman A, Zelefsky M, Wong J, Wentworth S, Vera R, Langley S: Comparative analysis of prostate-specific antigen free survival outcomes for patients with low, intermediate and high risk prostate cancer treatment by radical therapy. Results from the Prostate Cancer Results Study Group. BJU Int 2012, 109(Suppl 1):22-29. 
2. Taira AV1, Merrick GS, Butler WM, Galbreath RW, Lief J, Adamovich E, Wallner KE: Long-term outcome for clinically localized prostate cancer treated with permanent interstitial brachytherapy. Int I Radiat Oncol Biol Phys 2011, 79:1336-1342.

3. Sylvester JE, Grimm PD, Blasko JC, Millar J, Orio PF 3rd, Skoglund S, Galbreath RW, Merrick G: 15-Year biochemical relapse free survival in clinical Stage T1-T3 prostate cancer following combined external beam radiotherapy and brachytherapy; Seattle experience. Int I Radiat Oncol Biol Phys 2007, 67:57-64.

4. Hull GW, Rabbani F, Abbas F, Wheeler TM, Kattan MW, Scardino PT: Cancer control with radical prostatectomy alone in 1,000 consecutive patients. J Urol 2002, 167:528-534.

5. Han M1, Partin AW, Zahurak M, Piantadosi S, Epstein Jl, Walsh PC: Biochemical (prostate specific antigen) recurrence probability following radical prostatectomy for clinically localized prostate cancer. J Urol 2003, 169:517-523.

6. Kuban DA1, Levy LB, Cheung MR, Lee AK, Choi S, Frank S, Pollack A Long-term failure patterns and survival in a randomized dose-escalation trial for prostate cancer. Who dies of disease? Int I Radiat Oncol Biol Phys 2011, 79:1310-1317.

7. Cookson MS, Aus G, Burnett AL, Canby-Hagino ED, D'Amico AV, Dmochowski RR, Eton DT, Forman JD, Goldenberg SL, Hernandez J, Higano CS, Kraus SR, Moul JW, Tangen C, Thrasher JB, Thompson I: Variation in the definition of biochemical recurrence in patients treated for localized prostate cancer: the American Urological Association Prostate Guidelines for Localized Prostate Cancer Update Panel report and recommendations for a standard in the reporting of surgical outcomes. J Urol 2007, 177:540-545

8. Roach M 3rd, Hanks G, Thames H Jr, Schellhammer P, Shipley WU, Sokol GH, Sandler $\mathrm{H}$ : Defining biochemical failure following radiotherapy with or without hormonal therapy in men with clinically localized prostate cancer: recommendations of the RTOG-ASTRO Phoenix Consensus Conference. Int I Radiat Oncol Biol Phys 2006, 65:965-974.

9. American Urological Association (AUA): Guideline, Guideline for the Management of Clinically Localized Prostate Cancer. 2007 [http://www.auanet. org/education/guidelines/prostate-cancer.cfm]

10. European Association of Urology (EAU): Guideline. [http://www.uroweb.org]

11. National Comprehensive Cancer Network (NCCN): Clinical Practice Guidelines in Oncology, Prostate Cancer. [http://www.nccn.org]

12. D'Amico AV1, Whittington R, Malkowicz SB, Schultz D, Blank K, Broderick GA, Tomaszewski JE, Renshaw AA, Kaplan I, Beard CJ, Wein A: Biochemical outcome after radical prostatectomy, external beam radiation therapy, or interstitial radiation therapy for clinically localized prostate cancer. JAMA 1998, 280:969-974

13. Tanaka N, Asakawa I, Kondo H, Tanaka M, Fujimoto K, Hasegawa M, Konishi N, Hirao Y: Technical acquisition and dosimetric assessment of iodine-125 permanent brachytherapy in localized prostate cancer: our first series of 100 patients. Int J Urol 2009, 16:70-74.

14. Stock RG1, Stone NN, Cesaretti JA, Rosenstein BS: Biologically effective dose values for prostate brachytherapy: effects on PSA failure and posttreatment biopsy results. Int I Radiat Oncol Biol Phys 2006, 64:527-533.

15. Critz FA1, Benton JB, Shrake P, Merlin ML: 25 -Year disease-free survival rate after irradiation for prostate cancer calculated with the prostate specific antigen definition of recurrence used for radical prostatectomy. J Urol 2013, 189:878-883.

16. Stone NN, Stock RG, Cesaretti JA, Unger P: Local control following permanent prostate brachytherapy: effect of high biologically effective dose on biopsy results and oncologic outcomes. Int J Radiat Oncol Biol Phys 2010, 76:355-360.

17. Nielsen ME, Makarov DV, Humphreys E, Mangold L, Partin AW, Walsh PC: Is it possible to compare PSA recurrence-free survival after surgery and radiotherapy using revised ASTRO criterion-"nadir + 2"? Urology 2008, 72:389-395.

doi:10.1186/1748-717X-9-107

Cite this article as: Tanaka et al:: The biochemical recurrence-free rate in patients who underwent prostate low-dose-rate brachytherapy, using two different definitions. Radiation Oncology 2014 9:107.

\section{Submit your next manuscript to BioMed Central and take full advantage of:}

- Convenient online submission

- Thorough peer review

- No space constraints or color figure charges

- Immediate publication on acceptance

- Inclusion in PubMed, CAS, Scopus and Google Scholar

- Research which is freely available for redistribution 